\title{
Management of arrhythmias in heart failure. What a practicing physician should know in the current times
}

\author{
Rajesh Ramineni ${ }^{1}$, Mani Kumar Bheemarasetti ${ }^{1}$, Adrian Baranchuk ${ }^{2}$, \\ Tapasya Mandalapu ${ }^{1}$, Venkat K. Mukku ${ }^{1}$, Ken Fujise ${ }^{1}$, Alejandro Barbagelata ${ }^{1}$ \\ ${ }^{1}$ Department of Internal Medicine, Division of Cardiology, \\ University of Texas Medical Branch, Galveston, Texas, USA \\ ${ }^{2}$ Heart Rhythm Service, Kingston General Hospital, Queen's University, Kingston, Ontario, Canada
}

\begin{abstract}
Arrhythmias play a significant role in the mortality and morbidity as well as hospitalizations of patients who carry a diagnosis of congestive heart failure. With improving survival in a world of novel medications and devices, an understanding of the pathophysiology and management of these arrhythmias is crucial. Majority of the basic heart failure medications such as beta-blockers, angiotensin converting enzyme inhibitors/aldosterone receptor blockers and aldosterone antagonists play a pivotal role in prevention of sudden cardiac deaths which can be a direct/indirect result of these arrhythmias. Anti-arrhythmic drugs and implantable cardioverter-defibrillators were also beneficial in selected patients. Innovative electrophysiological techniques need to be considered in special situations. (Cardiol J 2012; 19, 6: 567-577)
\end{abstract}

Key words: arrhythmias, heart failure

\section{Introduction}

Heart failure (HF) is a progressively increasing epidemic of this century with an estimated 5.2 million American $(2.5 \%)$ currently being affected by it [1-3]. One in 5 adults greater than age forty will develop HF in their lifetime with an estimated direct and indirect health care burden of $\$ 33.2$ billion $[3,4]$. The rate of hospitalizations due to/or involving $\mathrm{HF}$ is progressively increasing (tripled from 1979 to 2004), making it currently the most common reason for admission in the elderly $[5,6]$. Arrhythmias play a major role in these frequent hospitalizations and office visits. Sudden cardiac death (SCD), a common result of arrhythmias contribute to more than $30-50 \%$ of all-cause mortality in pa- tients classified as New York Heart Association (NYHA) II-III [7]. Hence, an in-depth understanding of the concepts which aide in its management is of prime importance.

Majority of the abnormal heart rhythms generally tend to occur in patients with reduced left ventricular (LV) systolic function even though their presentation in $\mathrm{HF}$ with preserved ejection fraction (HFpEF) is not uncommon [8]. Arrhythmias encountered in $\mathrm{HF}$ are diverse but ventricular fibrillation (VF) and pulseless ventricular tachycardia (VT) are responsible for SCD in this cohort [9]. Atrial fibrillation (AF) and atrial flutter (AFL) are frequently associated with worse hemodynamic compromise in HF patients. Moreover, they are generally related to factors which enhance triggered

Address for correspondence: Alejandro Barbagelata, MD, Associate Professor, Department of Internal Medicine, Division of Cardiology, UTMB, 301 University Blvd., JSA 5.106, Galveston, TX 77555, USA, tel: 409-772-1533, fax: 409-772-4982, e-mail: nabarbag@utmb.edu 
arrhythmias, when compared to patients without HF [10].

With the advances in HF management prevention of arrhythmias is gaining greater significance. However, the currently available antiarrhythmic drugs have some limitations due to their side effects profile and proarrhythmic effect. The efficacy of implantable cardioverter-defibrillators (ICD) in preventing SCD had revolutionized the management strategies in the subgroup of patients with low left ventricular ejection fraction (LVEF) [11]. However, this therapy is not free of complications such as inappropriate shocks, advisories, and driving limitations [12-15].

Hence, we made an effort to outline the currently available studies and literature in this field with intent to guide a practicing physician in managing these complex arrhythmias in HF. All the recommendations will be grounded upon evidence-based medicine. However, therapy in any particular HF patient should be individualized, since each patient presents with unique set of challenges dictated by the particular arrhythmia, symptoms, co-morbidities, genetics and personal treatment preferences.

\section{Current standard heart failure medications}

Standard HF medications such as beta-blockers (BB), angiotensin converting enzyme (ACE) inhibitors and aldosterone receptor blockers (ARBs) have shown significant reduction in the risk of SCD. There are numerous trials done on these medications, but only a few of these directly addressed the impact on SCD. While the treatment and prevention of SCD demands specifically targeted therapy, this background standard medical therapy must not be ignored.

\section{Beta-blockers}

The use of BB in patients with chronic HF had been associated with improved morbidity and LV function in multiple trials some of which also reported their specific impact on SCD. The MERIT-HF study showed that metoprolol succinate reduced the all-cause mortality by $34 \%$, mortality due to sudden death by $41 \%$ and mortality due to progression of HF by $49 \%$ (Fig. 1) [7, 16]. Similarly, it was evident from the Cardiac Insufficiency Bisoprolol Study II (CIBIS-II) trial (which included equal number of ICM or NICM patients as well as NYHA III-IV) that bisoprolol reduced the risk of SCD by $41 \%$ (34\% reduction total mortality) [17]. The US Carvedilol Heart Failure Study Group have shown that use of

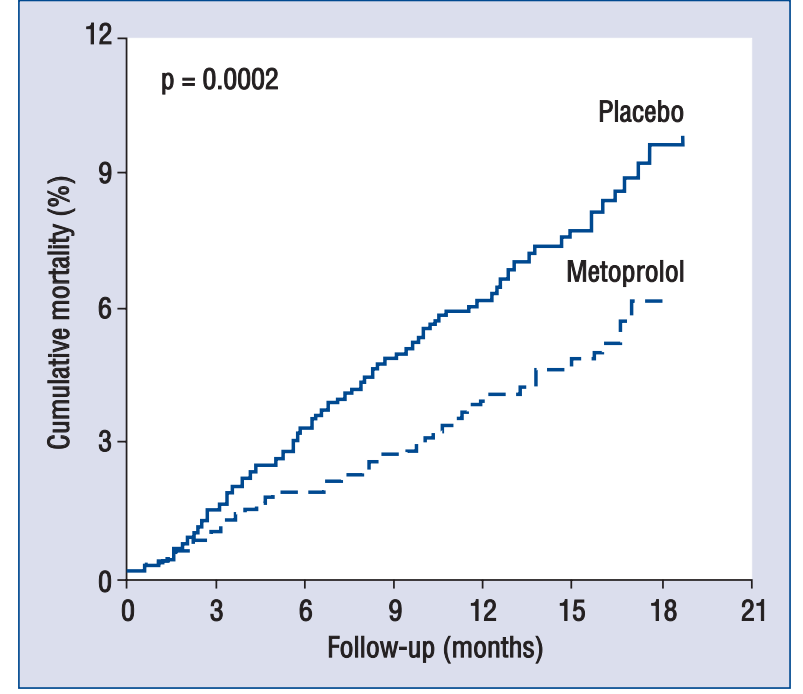

Figure 1. Effect of metoprolol in preventing sudden cardiac death (MERIT-HF study)

carvedilol (a non-selective blocker of beta-1 and alpha- 1 receptors) for $\mathrm{HF}$ resulted in a $56 \%$ reduction in SCD [18]. The COMET study demonstrated a further 3\% absolute reduction of SCD in carvedilol group compared to metoprolol tartrate (14\% vs. $17 \%$ ) [19]. Overall, there is $40-50 \%$ relative risk reduction or $4.4 \%$ absolute reduction in $\mathrm{SCD}$ with the use of BB.

\section{ACE inhibitors}

The importance of the effect of ACE inhibitors is very clear in light of trials highlighting their significant benefit in preventing SCD. The Vasodilator Heart Failure trial II (V-HEFT II) showed that the use of enalapril was associated with $39 \%$ reduction in SCD compared to the use of a combination of hydralazine/isosorbide dinitrate [20]. The AIRE Trial (Acute Infarction Ramipril Efficacy) showed that use of ramipril resulted in $27 \%$ reduction in $\mathrm{SCD}$ at 15 months vs. placebo [21]. Use of ramipril in the HOPE (Heart Outcomes Protection Evaluation) trial demonstrated a $21 \%$ reduction in SCD in patients classified as HF Stage A [22]. The TRACE (Trandolapril Cardiac Evaluation) (post AMI, EF $<35 \%$ vs. placebo at $24-50$ months) showed that trandolapril did reduce SCD by $24 \%$ (Fig. 2) [23]. Overall there is $20-40 \%$ relative risk reduction of $\mathrm{SCD}$ with the use of ACE inhibitors.

\section{Angiotensin receptor blockers}

Major trials involving ARBs including the ValHeFT, CHARM and VALIANT had mixed results on mortality benefits when compared to the ACE 


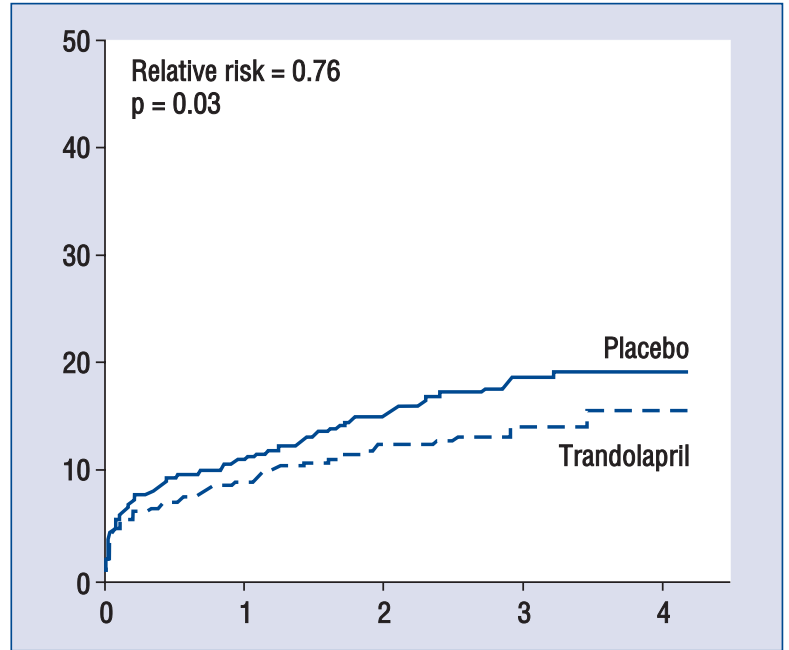

Figure 2. Effect of trandolapril in preventing sudden cardiac death (TRACE trail)

inhibitors and none of them specifically addressed their impact on SCD [24-26].

\section{Aldosterone antagonists}

The RALES (Randomized Aldactone Evaluation Study) revealed that spironolactone was associated with a $29 \%$ risk reduction of SCD (overall $30 \%$ reduction at 2 years) [27]. Preventing cellular efflux and overall loss of magnesium has been proposed as the potential mechanism [28]. In addition, the EPHESUS (Eplerenone Post AMI Heart failure Efficacy trial) proved that eplerenone also carried a similar benefit with an overall reduction of SCD by $21 \%$ (Fig. 3). Necessity of aldosterone antagonism in chronic severe systolic HF as well as HF after myocardial infarction has been proven beyond doubt [29]. Of late, there is growing evidence supporting the use of aldosterone antagonists even in mild systolic HF in an effort to prevent SCD [30]. Overall, there is a $20-30 \%$ risk reduction of SCD by using aldosterone antagonists.

\section{Antiarrhythmic drugs}

All antiarrhythmic drugs possess potential proarrhythmic toxicity and in general class IA and IC drugs are contraindicated in HF patients. Class III agents such as amiodarone, dofetilide and azimilide have a low incidence of ventricular proarrhythmias (Table 1) [31]. A recent meta-analysis showed that amiodarone reduces the risk of SCD by $29 \%$ and cardiovascular disease by $18 \%$, and

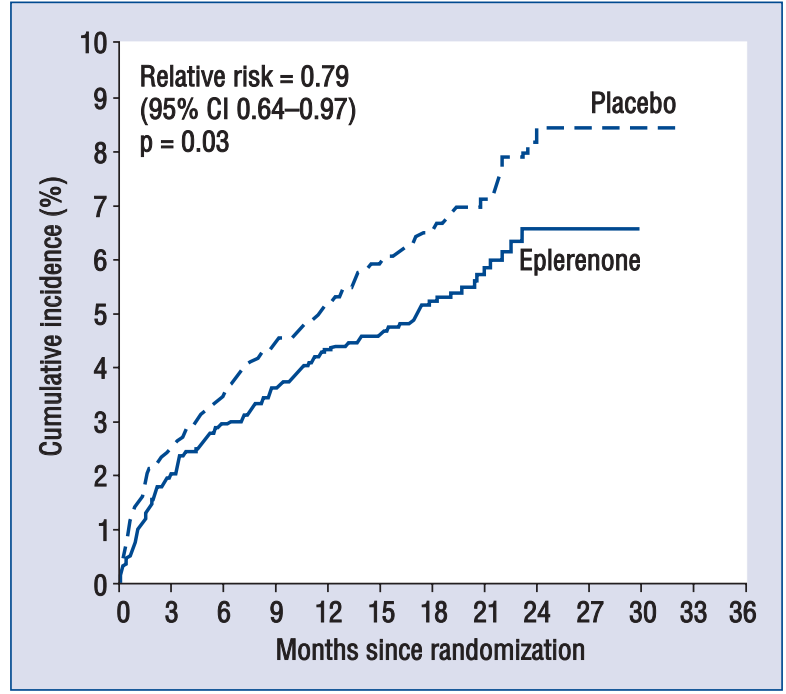

Figure 3. Sudden cardiac death in EPHESUS trial, comparing patients randomized to the selective aldosterone antagonist eplerenone versus placebo.

therefore, represents a viable alternative in patients who are not eligible for or who do not have access to ICD therapy for the prevention of SCD. This drug can be considered as adjuvant therapy to ICD in preventing recurrent shocks [32]. However, amiodarone therapy is neutral with respect to all-cause mortality and is associated with a 2 and 5 fold increased risk of pulmonary and thyroid toxicity respectively [33]. Dofetilide and azimilide did not demonstrate a mortality benefit either [34-36]. In summary, there is little role for prophylactic antiarrhythmic medications for the primary prevention of SCD in patients with HF except amiodarone. The benefits of the ICDs demonstrated to be superior to the effect of antiarrhythmic drugs for primary prevention of SCD.

\section{Implantable cardioverter-defibrillator}

ICDs have gained a lot of popularity in the management of SCD replacing the use of antiarrhythmic drugs in primary prevention and relegated their role as co-adjuvant treatment for reducing the incidence of appropriate (or inappropriate incase of $\mathrm{AF}$ ) shocks in patients with pre-existing ICDs [32]. It uses antitachycardia pacing (ATP), cardioversion, defibrillation and pacing for bradycardia to achieve its goal. Trials that looked at primary prevention using ICDs mainly included patients with $\mathrm{EF}<35 \%$ and NYHA class II-IV. From all these trials, it was evident that patients who have EF $<35 \%$ and experiencing NYHA class II-III symp- 


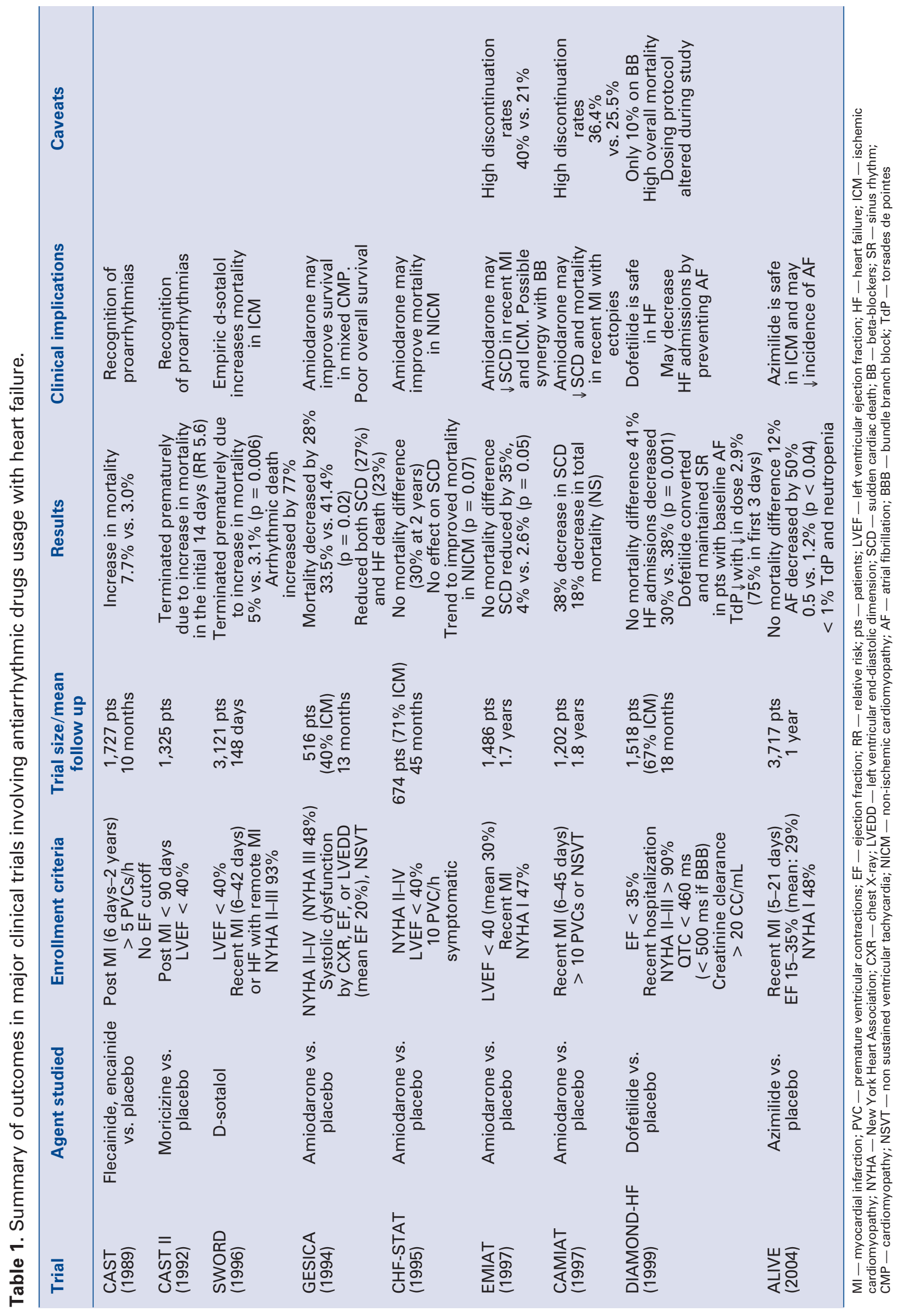


toms despite optimal medical therapy are at high risk of SCD and thus this population will benefit with the use of an ICD (Table 2) [37-40].

Given the significant increase in use of ICDs, a clear understanding of scenarios when they deliver therapy and management of arrhythmias in these situations is crucial.

\section{ICD shocks}

Patients implanted with ICDs will experience shocks occasionally, which can be distressful. Attention needs to be paid to psychological and emotional consequences of ICD therapies. Some of the patients may refer a shock when in fact the device did not deliver therapy. Interrogation of the device is mandatory, not only to confirm the type of delivered therapy, but also to reassure the patient on how to react when a shock occurs. Initial evaluation of the patient who has received ICD discharges should focus upon any possible precipitants for arrhythmias, including electrolyte disturbances, myocardial ischemia/infarction, worsening HF or drug toxicities. Device interrogation will allow proper classification of the shock (appropriate vs. inappropriate).

Appropriate shocks is the one delivered for VT/VF. Recurrent appropriate shocks (also known as "electrical storm") need immediate medical attention, since it can lead to reduced survival [41, 42]. These patients are also at increased risk for non-SCD due to progression of ventricular dysfunction. Efforts to decrease device therapies should include programming ATP to terminate VT and the use of drugs to prevent VT in addition to the ICD [32]. ATP is a painless technique which involves detection of VT and timely delivery of rapid sequential ventricular pacing at rates, thereby overriding the underlying arrhythmia [43]. Patients who receive appropriate shocks were noted to have substantially higher ventricular arrhythmia burden and poor survival compared to patients treated with ATP-alone [44]. Adjunctive pharmacotherapy, in addition to ATP, was shown to reduce the incidence of shocks. Amiodarone along with $\mathrm{BB}$ reduced the incidence of shocks from $41 \%$ to $29 \%$ compared to $\mathrm{BB}$ alone [32]. However, celivarone a new noniodinated benzofuran derivative with an action similar to amiodarone failed to show similar benefit of reducing appropriate ICD therapies or SCD [45]. Use of sotalol was noted to decrease shock free survival by $49 \%$ compared to placebo. Azimilide was also shown to decrease the number of symptomatic arrhythmias treated by ATP/shock therapy in addition to reducing Emergency Room visits and hospitalizations [46, 47]. Recurrent arrhythmias lead- ing to appropriate shocks should prompt adequate evaluation for undiagnosed ischemia as the culprit with a possibility of revascularization as needed. Finally, VT ablation should also be considered in order to modify the anatomical substrate, reducing the number of ICD discharges [48].

Inappropriate shocks/atrial fibrillation/ /atrial flutter. Sometimes ICD can misread other rhythms as VT/VF especially when the rate of the on-going arrhythmia is greater than the pre-set detection rate of the ICD. In this scenario, the ICD can deliver a shock, which is labelled as inappropriate. Inappropriate ICD shocks were associated with increased risk of all-cause mortality [42, 49]. The most common cause for these shocks are AF/ /AFL [49]. AF and HF are commonly encountered together, either condition predisposing to the other. The presence of each condition increases the morbidity and mortality associated with the other and their coexistence complicates patient management [50]. Of the 2 principal therapeutic strategies in managing $\mathrm{AF}$, rate control and rhythm control, neither has been shown to be superior to the other in terms of survival, despite better quality of life and LV function in patients with sinus rhythm compared to those in AF (Table 3) [51, 52]. Patients with ICD are preferred to be in sinus rhythm, to prevent inappropriate shocks and readmissions. If a cardioversion is planned, it is recommended that all patients undergo transesophageal echocardiogram to rule out left atrial thrombus and preferred to be fully anticoagulated for at least 3 weeks prior the planned procedure. Anticoagulation has to be continued for at least 4-6 weeks after cardioversion despite restoring a normal rhythm. The use of antiarrhythmic agents after cardioversion can help maintain sinus rhythm and prevent inappropriate shocks [53]. Amiodarone along with $\mathrm{BB}$ reduces the incidence of inappropriate shocks from $41 \%$ to $29 \%$ compared to $\mathrm{BB}$ alone [54]. Digoxin can be used in patients with permanent and persistent $\mathrm{AF}$ as a rate control strategy in order to prevent inappropriate shocks [55].

Catheter ablation of $\mathrm{AF}$ is a newer technique that should be considered in a selected population of patients with HF. Atrio Ventricular Junction Ablation (AVJA) and pulmonary vein isolation are the two predominant ablation strategies used to treat $\mathrm{AF}$ patients who are refractory to drugs. In patients with congestive HF refractory to drugs, AVJA with biventricular pacing (BiV) for cardiac resynchronization has shown an improvement in exercise capacity and quality of life [56]. Overuse of right ventricular (RV) pacing alone in scenarios such as AVJA has a tendency to increase threshold for 


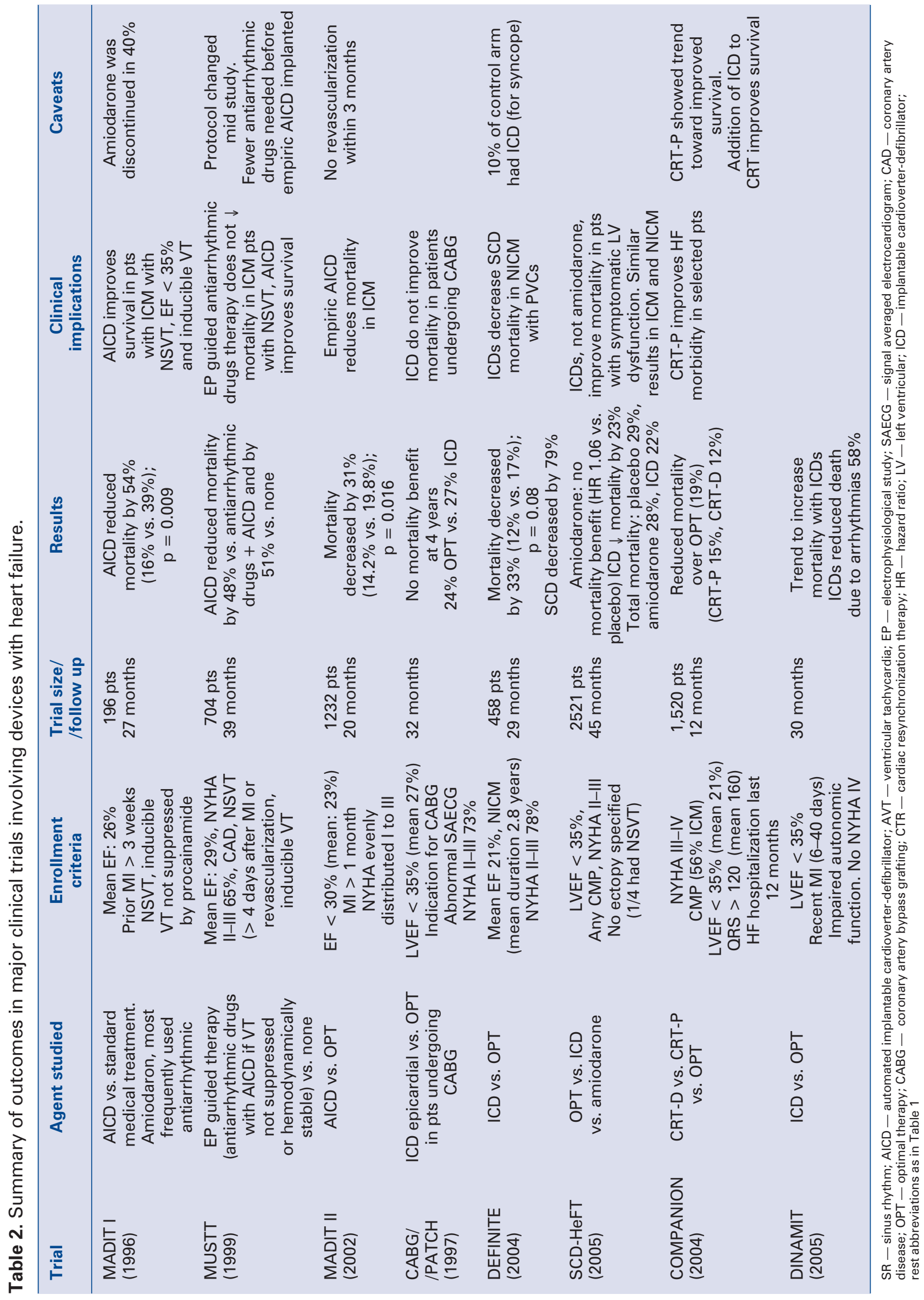




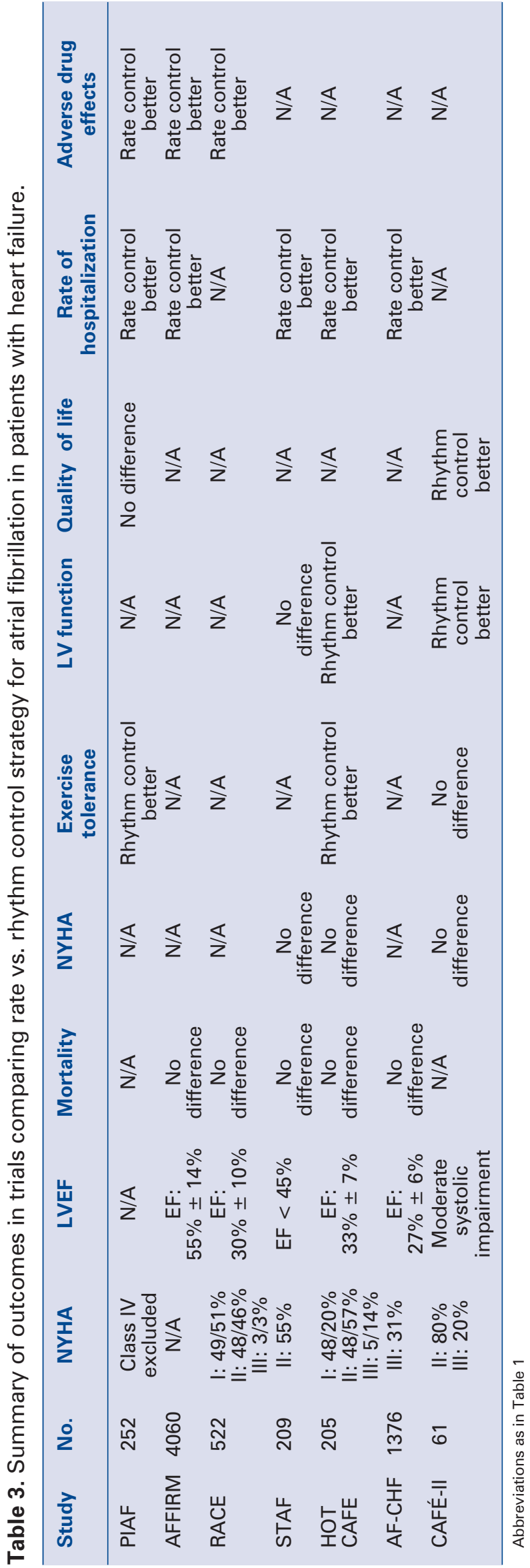

shocks as well as cause HF exacerbation [57, 58]. When compared to RV apical pacing alone, BiV pacing resulted in improvement in LVEF [59]. However, in a head-to-head comparison, pulmonary vein antrum ablation was shown to be superior to AVJA [60]. Cure of AF in patients with congestive HF resulted in more significant morphological and functional improvements than AVJA [60]. Restoration and maintenance of sinus rhythm by catheter ablation without the use of drugs in patients with congestive $\mathrm{HF}$ and $\mathrm{AF}$ significantly improve cardiac function, symptoms, exercise capacity, and quality of life (Table 4) [50,61, 62].

\section{Cardiac resynchronization therapy}

Patients with NYHA class III-IV who has QRS prolongation more than $120 \mathrm{~s}$ and $\mathrm{EF}<35 \%$, were noted to benefit from cardiac resynchronization therapy (CRT) when used in conjunction with ICD (CRT-D) (recent data suggest that the benefit is more pronounced when the QRS duration is longer than $150 \mathrm{~ms}$ ) [63-65]. CRT-D in COMPANION trial showed reduction of SCD by $56 \%$ compared to CRT alone. These benefits were not reflected in NYHA class I-II patients in the RAFT trial [66]. However, a specific subgroup of patients with NYHA class I-II (LVEF $\leq 30 \%)$ and a left bundle branch block (LBBB) were noted to derive significant benefit from CRT-D with reduction in HF progression as well as a reduction in the risk of ventricular tachyarrhythmias [67]. Patients with CRT also seem to have less recurrence of $\mathrm{AF}$, which is attributed to atrial reverse-remodeling and a shorter $\mathrm{AF}$ duration [68].

\section{Non-ICD population}

Patients diagnosed of $\mathrm{HFpEF}$ and advanced $\mathrm{HF}$ (NYHA IV) patients where ICD is not indicated can be considered under this category. Previous studies have indicated that this cohort constitutes $1.2 \%$ of all the patients with $\mathrm{HFpEF}$ and are at eight times greater risk of death [69]. These patients have preserved systolic function without known scar or fibrotic tissue burden, which is considered a potential substrate for arrhythmias in the systolic HF group. They have an annual death rate of $5.6 \%$ per the observations in I-PRESERVE HFpEF cohort of which $26 \%$ are due to sudden death [70]. Multiple hypotheses have been proposed to explain this pathological process [71], however consensus has not been reached so far making treatment plans complex. The management of arrhythmias in this cohort can be divided into ventricular and supraventricular arrhythmias. 
Table 4. Summary of outcomes in trials involving catheter ablation strategy for atrial fibrillation in patients with heart failure.

\begin{tabular}{lccccccc}
\hline Study & No. & $\begin{array}{c}\text { Baseline NYHA } \\
\text { class }\end{array}$ & $\begin{array}{c}\text { Mean follow up } \\
\text { (months) }\end{array}$ & $\begin{array}{c}\text { Success } \\
(\%)\end{array}$ & $\begin{array}{c}\text { Change in } \\
\text { LVEF (\%) }\end{array}$ & $\begin{array}{c}\text { Exercise } \\
\text { capacity }\end{array}$ & $\begin{array}{c}\text { Quality } \\
\text { of life }\end{array}$ \\
\hline HSU & 58 & $2.3 \pm 0.5$ & 12 & 78 & $35-56$ & Improved & Improved \\
Chen & 94 & $\begin{array}{c}\text { Class II: } 30 \% \\
\text { Class III: } 68 \%\end{array}$ & 14 & 73 & $36-41$ & N/A & Improved \\
& & $\begin{array}{c}\text { Class IV: } 2 \% \\
2.8 \pm 0.1\end{array}$ & 14 & 87 & $33-47$ & Improved & Improved \\
Tondo & 40 & N/A & 20 & 86 & $42-56$ & N/A & N/A \\
Gentlesk & 67 & & & & & &
\end{tabular}

Abbreviations as in Table 1

\section{Ventricular arrhythmias}

Optimization of medical treatment should include BB, ACE inhibitor/ARBs and aldosterone antagonists in order to prevent SCD. Amiodarone is a useful addition in preventing SCD in patients with advanced HF. However, its side effect profile needs to be closely monitored. Atorvastatin therapy was associated with decreased incidence of SCD in patients with advanced chronic HF [72]. However, larger on-going studies are needed to confirm this hypothesis.

\section{Supraventricular arrhythmias}

Atrial fibrillation is by far the most frequent arrhythmia in this clinical scenario. Major progress has been made in the management of $\mathrm{AF}$ in the last few years with multiple new medications joining the currently existing armamentarium of amiodarone, digoxin, $\mathrm{BB}$ and calcium channel blockers. The ADONIS (American-Australian-African study) and European Trial EURIDIS, both controlled trials with over 600 patients each, showed that dronedarone is significantly more effective than placebo in maintaining sinus rhythm and in reducing the ventricular rate during recurrence of AF [73, 74]. Dronedarone also reduced the incidence of hospitalization due to cardiovascular events or death in patients with $\mathrm{AF}$ [75]. However, in patients with severe HF and LV systolic dysfunction (NYHA III-IV), treatment with dronedarone was associated with increased early mortality related to the worsening of HF [76] and hence is contraindicated. A recent study also showed increase in major cardiac events with its use in patients with permanent AF [77]. Azimilide in the ALIVE study also showed a decrease in the incidence of AF by $50 \%$ [78]. Dofetilide in DIAMOND HF was shown to be safe along with decrease in $\mathrm{HF}$ readmissions by $21 \%$, which was speculated to be through decrease in the incidence of AF [79].

GISSI-HF study revealed a beneficial effect of rosuvastatin in reducing the incidence of $\mathrm{AF}$ in patients with HF. Larger studies are needed to provide a definitive answer to this question [80]. An ovine HF study showed chronic n-3 PUFAs use protected against adverse atrial remodeling by preventing atrial enlargement, fibrosis and conduction abnormalities leading to shorter AF episodes [81].

\section{Newer management strategies}

A resting heart rate above $70 \mathrm{bpm}$ is an independent risk factor in systolic HF [82]. If this high heart rate persists despite the maximal tolerated $\mathrm{BB}$ dose, isolated heart rate reduction by ivabradine may lower the rate of hospital admissions due to worsening HF [83]. Iron deficiency should be corrected independently of the presence of anemia to improve symptoms and exercise capacity. Since sodium overload play an important role in the pathophysiology of $\mathrm{HF}$, the use of ranolazine which blocks late sodium current is currently being studied for reduction of cardiac arrhythmias [84].

\section{Arrhythmias and mechanical circulatory support}

There is growing cohort of patients with advanced HF currently being managed on mechanical circulatory support. These patients are at greater risk of arrhythmias of both atrial and ventricular origin especially post surgery $[85,86]$. Increase in filling pressures, mitral and tricuspid regurgitations leading to chamber remodeling and the presence of inflow cannula in the LV are some of the inciting pathophysiological mechanisms proposed to explain this surge in events. Management of atrial arrhythmias remain the same as with other HF patients. 
Ventricular tachycardias in this setting are generally managed by lowering the left ventricular assist device speeds along with $\mathrm{BB}$ and antiarrhythmic drugs such as amiodarone, dofetilide or mexilitine [87]. However, the rates of arrhythmias usually come down farther from the implant allowing scaling down the use of antiarrhythmic drugs. In very rare situations mechanical circulatory support is considered in management of patients with refractory ventricular arrhythmias who failed multiple attempts of medical therapy and ablations.

\section{Conclusions}

Management of arrhythmias in patients with HF remains a challenge. This field is constantly evolving and the addition of newer techniques and medications do not stop growing. This brief review was intended to provide a guide to the practicing physicians based on currently available evidence.

\section{Conflict of interest: none declared}

\section{References}

1. Braunwald E. Shattuck lecture: Cardiovascular medicine at the turn of the millennium: Triumphs, concerns, and opportunities. N Engl J Med, 1997; 337: 1360-1369.

2. Croft JB, Giles WH, Pollard RA, Keenan NL, Casper ML, Anda RF. Heart failure survival among older adults in the United States: A poor prognosis for an emerging epidemic in the Medicare population. Arc Internal Med, 1999; 159: 505-510.

3. Roger VL, Go AS, Lloyd-Jones DM et al. Heart disease and stroke statistics: 2011 update: A report from the American Heart Association. Circulation, 2011; 123: e18-e209.

4. Lloyd-Jones DM, Larson MG, Leip EP et al. Lifetime risk for developing congestive heart failure: The Framingham Heart Study. Circulation, 2002; 106: 3068-3072.

5. DeFrances CJ, Cullen KA, Kozak LJ. National Hospital Discharge Survey: 2005 annual summary with detailed diagnosis and procedure data. Vital Health Stat, 2007; 13: 1-209.

6. Fang J, Mensah GA, Croft JB, Keenan NL. Heart failure-related hospitalization in the U.S., 1979 to 2004. J Am Coll Cardiol, 2008; 52: 428-434.

7. Goldstein S, Hjalmarson A. The mortality effect of metoprolol $\mathrm{CR} / \mathrm{XL}$ in patients with heart failure: Results of the MERIT-HF Trial. Clin Cardiol, 1999; 22 (suppl. 5): V30-V35.

8. Sweeney MO, Hellkamp AS, Ellenbogen KA, Lamas GA. Reduced ejection fraction, sudden cardiac death, and heart failure death in the mode selection trial (MOST): implications for device selection in elderly patients with sinus node disease. J Cardiovasc Electrophysiol, 2008; 19: 1160-1166.

9. Huikuri HV, Castellanos A, Myerburg RJ. Sudden death due to cardiac arrhythmias. The N Engl J Med, 2001; 345: 1473-1482.

10. Pogwizd SM, Bers DM. Cellular basis of triggered arrhythmias in heart failure. Trends Cardiovasc Med, 2004; 14: 61-66.

11. Nanthakumar K, Epstein AE, Kay GN, Plumb VJ, Lee DS. Prophylactic implantable cardioverter-defibrillator therapy in pa- tients with left ventricular systolic dysfunction: A pooled analysis of 10 primary prevention trials. J Am Coll Cardiol, 2004; 44: 2166-2172.

12. Matlock DD, Peterson PN, Heidenreich PA et al. Regional variation in the use of implantable cardioverter-defibrillators for primary prevention: Results from the National Cardiovascular Data Registry. Circ Cardiovasc Qual Outcomes, 2011; 4: 114-121.

13. Goldenberg I, Moss AJ, Hall WJ et al. Causes and consequences of heart failure after prophylactic implantation of a defibrillator in the multicenter automatic defibrillator implantation trial II. Circulation, 2006; 113: 2810-2817.

14. Mark DB, Anstrom KJ, Sun JL et al. Quality of life with defibrillator therapy or amiodarone in heart failure. N Engl J Med, 2008; 359: 999-1008.

15. Washizuka T, Chinushi M, Kazama R et al. Inappropriate discharges of intravenous implantable cardioverter defibrillators owing to lead failure. Int Heart J, 2005; 46: 909-913.

16. Hjalmarson A, Fagerberg B. MERIT-HF mortality and morbidity data. Basic Res Cardiol, 2000; 95 (suppl. 1): I98-I103.

17. The Cardiac Insufficiency Bisoprolol Study II (CIBIS-II): A randomised trial. Lancet, 1999; 353: 9-13.

18. Packer M, Bristow MR, Cohn JN et al. The effect of carvedilol on morbidity and mortality in patients with chronic heart failure. U.S. Carvedilol Heart Failure Study Group. N Engl J Med, 1996; 334: 1349-1355.

19. Poole-Wilson P, Swedberg K, Cleland J et al. Comparison of carvedilol and metoprolol on clinical outcomes in patients with chronic heart failure in the Carvedilol Or Metoprolol European Trial (COMET): Randomised controlled trial. Lancet, 2003; 362: 7-13.

20. Fletcher R, Cintron G, Johnson G, Orndorff J, Carson P, Cohn J. Enalapril decreases prevalence of ventricular tachycardia in patients with chronic congestive heart failure. The V-HeFT II VA Cooperative Studies Group. Circulation, 1993; 87: VI49-VI55.

21. Cleland J, Erhardt L, Murray G, Hall A, Ball S. Effect of ramipril on morbidity and mode of death among survivors of acute myocardial infarction with clinical evidence of heart failure. A report from the AIRE Study Investigators. Eur Heart J, 1997; 18: 41-51.

22. Teo K, Mitchell L, Pogue J et al. Effect of ramipril in reducing sudden deaths and nonfatal cardiac arrests in high-risk individuals without heart failure or left ventricular dysfunction. Circulation, 2004; 110: 1413-1417.

23. Køber L, Torp-Pedersen C, Carlsen JE et al. A clinical trial of the angiotensin-converting-enzyme inhibitor trandolapril in patients with left ventricular dysfunction after myocardial infarction. Trandolapril Cardiac Evaluation (TRACE) Study Group. N Engl J Med, 1995; 333: 1670-1676.

24. Granger CB, McMurray JJ, Yusuf S et al. Effects of candesartan in patients with chronic heart failure and reduced left-ventricular systolic function intolerant to angiotensin-converting-enzyme inhibitors: The CHARM-Alternative trial. Lancet, 2003; 362: 772-776.

25. Cohn JN, Tognoni G, Investigators VHFT. A randomized trial of the angiotensin-receptor blocker valsartan in chronic heart failure. N Engl J Med, 2001; 345: 1667-1675.

26. Pfeffer MA, McMurray JJ, Velazquez EJ et al. Valsartan, captopril, or both in myocardial infarction complicated by heart failure, left ventricular dysfunction, or both. N Engl J Med, 2003; 349: 1893-906.

27. Kulbertus H. Study of the month. The RALES study (randomized aldactone evaluation study). Rev Med Liege, 1999; 54: 770-772. 
28. Gao X, Peng L, Adhikari CM, Lin J, Zuo Z. Spironolactone reduced arrhythmia and maintained magnesium homeostasis in patients with congestive heart failure. J Card Fail, 2007; 13: 170-1777.

29. Pitt B, Gheorghiade M, Zannad F et al. Evaluation of eplerenone in the subgroup of EPHESUS patients with baseline left ventricular ejection fraction $<$ or $=30 \%$. Eur J Heart Fail, 2006; 8: 295-301.

30. Zannad F, McMurray JJ, Krum H et al. Eplerenone in patients with systolic heart failure and mild symptoms. N Engl J Med, 2011; 364: 11-21.

31. McAlister FA, Teo KK. Antiarrhythmic therapies for the prevention of sudden cardiac death. Drugs, 1997; 54: 235-252.

32. Connolly SJ, Dorian P, Roberts RS et al. Comparison of beta-blockers, amiodarone plus beta-blockers, or sotalol for prevention of shocks from implantable cardioverter defibrillators: the OPTIC Study: A randomized trial. JAMA, 2006; 295: 165-171.

33. Piccini JP, Berger JS, O'Connor CM. Amiodarone for the prevention of sudden cardiac death: A meta-analysis of randomized controlled trials. Eur Heart J, 2009; 30: 1245-1253.

34. Kober L, Bloch Thomsen PE, Moller M et al. Effect of dofetilide in patients with recent myocardial infarction and left-ventricular dysfunction: A randomised trial. Lancet, 2000; 356: 2052-1058.

35. Torp-Pedersen C, Moller M, Bloch-Thomsen PE et al. Dofetilide in patients with congestive heart failure and left ventricular dysfunction. Danish Investigations of Arrhythmia and Mortality on Dofetilide Study Group. N Engl J Med, 1999; 341: 857-865.

36. Camm AJ, Karam R, Pratt CM. The azimilide post-infarct survival evaluation (ALIVE) trial. Am J Cardiol, 1998; 81: 35D-39D

37. Bigger JJ, Whang $\mathrm{W}$, Rottman J et al. Mechanisms of death in the CABG Patch trial: A randomized trial of implantable cardiac defibrillator prophylaxis in patients at high risk of death after coronary artery bypass graft surgery. Circulation, 1999; 99: 1416-1421.

38. Greenberg H, Case R, Moss A et al. Analysis of mortality events in the Multicenter Automatic Defibrillator Implantation Trial (MADIT-II). J Am Coll Cardiol, 2004; 43: 1459-1465.

39. Bardy G, Lee K, Mark D et al. Amiodarone or an implantable cardioverter-defibrillator for congestive heart failure. N Engl J Med, 2005; 352: 225-237.

40. Kadish A, Dyer A, Daubert J et al. Prophylactic defibrillator implantation in patients with nonischemic dilated cardiomyopathy. N Engl J Med, 2004; 350: 2151-2158.

41. Moss AJ, Greenberg H, Case RB et al. Long-term clinical course of patients after termination of ventricular tachyarrhythmia by an implanted defibrillator. Circulation, 2004; 110: 3760-3765.

42. Poole JE, Johnson GW, Hellkamp AS et al. Prognostic importance of defibrillator shocks in patients with heart failure. N Engl J Med, 2008; 359: 1009-1017.

43. Wathen M. Implantable cardioverter defibrillator shock reduction using new antitachycardia pacing therapies. Am Heart J, 2007; 153: 44-52.

44. Sweeney MO, Sherfesee L, DeGroot PJ, Wathen MS, Wilkoff BL. Differences in effects of electrical therapy type for ventricular arrhythmias on mortality in implantable cardioverter-defibrillator patients. Heart Rhythm, 2010; 7: 353-360.

45. Kowey PR, Crijns HJ, Aliot EM et al. Efficacy and safety of celivarone, with amiodarone as calibrator, in patients with an implantable cardioverter-defibrillator for prevention of implantable cardioverter-defibrillator interventions or death: The ALPHEE study. Circulation, 2011; 124: 2649-2660.
46. Dorian P, Borggrefe M, Al-Khalidi HR et al. Placebo-controlled, randomized clinical trial of azimilide for prevention of ventricular tachyarrhythmias in patients with an implantable cardioverter defibrillator. Circulation, 2004; 110: 3646-3654.

47. Dorian P, Al-Khalidi HR, Hohnloser SH et al. Azimilide reduces emergency department visits and hospitalizations in patients with an implantable cardioverter-defibrillator in a placebo-controlled clinical trial. J Am Coll Cardiol, 2008; 52: 1076-1083.

48. Stevenson WG, Wilber DJ, Natale A et al. Irrigated radiofrequency catheter ablation guided by electroanatomic mapping for recurrent ventricular tachycardia after myocardial infarction: The multicenter thermocool ventricular tachycardia ablation trial. Circulation, 2008; 118: 2773-2782.

49. Daubert JP, Zareba W, Cannom DS et al. Inappropriate implantable cardioverter-defibrillator shocks in MADIT II: frequency, mechanisms, predictors, and survival impact. J Am Coll Cardiol, 2008; 51: 1357-1365.

50. Anter E, Jessup M, Callans DJ. Atrial fibrillation and heart failure: Treatment considerations for a dual epidemic. Circulation, 2009; 119: 2516-2525.

51. Roy D, Talajic M, Nattel S et al. Rhythm control versus rate control for atrial fibrillation and heart failure. New Engl J Med, 2008; 358: 2667-2677.

52. Shelton RJ, Clark AL, Goode K et al. A randomised, controlled study of rate versus rhythm control in patients with chronic atrial fibrillation and heart failure: CAFE-II Study. Heart, 2009; 95: 924-930.

53. Fuster V, Ryden LE, Cannom DS et al. 2011 ACCF/AHA/HRS focused updates incorporated into the ACC/AHA/ESC 2006 guidelines for the management of patients with atrial fibrillation: A report of the American College of Cardiology Foundation/ /American Heart Association Task Force on practice guidelines. Circulation, 2011; 123: e269-e367.

54. Connolly S, Dorian P, Roberts R et al. Comparison of beta-blockers, amiodarone plus beta-blockers, or sotalol for prevention of shocks from implantable cardioverter defibrillators: the OPTIC Study: A randomized trial. JAMA, 2006; 295: 165-171.

55. Hunt SA, Abraham WT, Chin MH et al. 2009 focused update incorporated into the ACC/AHA 2005 Guidelines for the Diagnosis and Management of Heart Failure in Adults: A report of the American College of Cardiology Foundation/American Heart Association Task Force on Practice Guidelines: Developed in collaboration with the International Society for Heart and Lung Transplantation. Circulation, 2009; 119: e391-e479.

56. Brignole M, Gammage M, Puggioni E et al. Comparative assessment of right, left, and biventricular pacing in patients with permanent atrial fibrillation. Eur Heart J, 2005; 26: 712-722.

57. Gardiwal A, Yu H, Oswald $\mathrm{H}$ et al. Right ventricular pacing is an independent predictor for ventricular tachycardia/ventricular fibrillation occurrence and heart failure events in patients with an implantable cardioverter-defibrillator. Europace, 2008; 10: 358-363.

58. Smit MD, Van Dessel PF, Nieuwland W et al. Right ventricular pacing and the risk of heart failure in implantable cardioverter-defibrillator patients. Heart Rhythm, 2006; 3: 1397-1403.

59. Doshi RN, Daoud EG, Fellows $C$ et al. Left ventricular-based cardiac stimulation post AV nodal ablation evaluation (the PAVE study). J Cardiovascular Electrophysiol, 2005; 16: 1160-1165.

60. Khan MN, Jaïs P, Cummings J et al. Pulmonary-vein isolation for atrial fibrillation in patients with heart failure. N Engl J Med, 2008; 359: 1778-1785. 
61. Hsu LF, Jaïs P, Sanders $P$ et al. Catheter ablation for atrial fibrillation in congestive heart failure. N Engl J Med, 2004; 351: 2373-2383.

62. Seiler J, Stevenson WG. Atrial fibrillation in congestive heart failure. Cardiol Rev, 2010; 18: 38-50.

63. Moss AJ, Hall WJ, Cannom DS et al. Cardiac-resynchronization therapy for the prevention of heart-failure events. N Engl J Med, 2009; 361: 1329-1338.

64. Cleland J, Daubert J, Erdmann E et al. Longer-term effects of cardiac resynchronization therapy on mortality in heart failure [the CArdiac REsynchronization-Heart Failure (CARE-HF) trial extension phase]. Eur Heart J, 2006; 27: 1928-1932.

65. Bristow M, Saxon L, Boehmer J et al. Cardiac-resynchronization therapy with or without an implantable defibrillator in advanced chronic heart failure. N Engl J Med, 2004; 350: 2140-2150 .

66. Tang AS, Wells GA, Talajic M et al. Cardiac-resynchronization therapy for mild-to-moderate heart failure. N Engl J Med, 2010; 363: 2385-2395.

67. Zareba W, Klein H, Cygankiewicz I et al. Effectiveness of Cardiac Resynchronization Therapy by QRS Morphology in the Multicenter Automatic Defibrillator Implantation Trial-Cardiac Resynchronization Therapy (MADIT-CRT). Circulation, 2011; 123: 1061-1072.

68. Lellouche N, De Diego C, Vaseghi M et al. Cardiac resynchronization therapy response is associated with shorter duration of atrial fibrillation. Pacing Clin Electrophysiol, 2007; 30: 1363-1368.

69. Ahmed A, Aronow WS, Fleg JL. Higher New York Heart Association classes and increased mortality and hospitalization in patients with heart failure and preserved left ventricular function. Am Heart J, 2006; 151: 444-450.

70. Zile MR, Gaasch WH, Anand IS et al. Mode of death in patients with heart failure and a preserved ejection fraction: Results from the Irbesartan in Heart Failure With Preserved Ejection Fraction Study (I-Preserve) trial. Circulation, 2010; 121: 1393-1405.

71. Udelson JE. Heart failure with preserved ejection fraction. Circulation, 2011; 124: e540-e543.

72. Vrtovec B, Okrajsek R, Golicnik A et al. Atorvastatin therapy may reduce the incidence of sudden cardiac death in patients with advanced chronic heart failure. J Cardiac Failure, 2008; 14: 140-144.

73. Duray GZ, Schmitt J, Hohnloser SH. Dronedarone therapy in atrial fibrillation: A summary of recent controlled trials. J Cardiovasc Pharmacol Ther, 2010; 15: 19S-23S.

74. Singh BN, Connolly SJ, Crijns HJ et al. Dronedarone for maintenance of sinus rhythm in atrial fibrillation or flutter. $\mathrm{N} \mathrm{Engl}$ J Med, 2007; 357: 987-999.
75. Hohnloser SH, Crijns HJ, van Eickels M et al. Effect of dronedarone on cardiovascular events in atrial fibrillation. N Engl J Med, 2009; 360: 668-678.

76. Køber L, Torp-Pedersen C, McMurray JJ et al. Increased mortality after dronedarone therapy for severe heart failure. $\mathrm{N} \mathrm{Engl}$ J Med, 2008; 358: 2678-2687.

77. Connolly SJ, Camm AJ, Halperin JL; for the PALLAS Investigators. Dronedarone in high-risk permanent atrial fibrillation. N Engl J Med, 2011; 10.1056/NEJMoa1109867.

78. Pratt CM, Singh SN, Al-Khalidi HR et al. The efficacy of azimilide in the treatment of atrial fibrillation in the presence of left ventricular systolic dysfunction: Results from the Azimilide Postinfarct Survival Evaluation (ALIVE) trial. J Am Coll Cardiol, 2004; 43: 1211-1216.

79. Pedersen OD, Brendorp B, Elming H, Pehrson S, Køber L, Torp-Pedersen C. Does conversion and prevention of atrial fibrillation enhance survival in patients with left ventricular dysfunction? Evidence from the Danish Investigations of Arrhythmia and Mortality ON Dofetilide/(DIAMOND) study. Card Electrophysiol Rev, 2003; 7: 220-224.

80. Maggioni AP, Fabbri G, Lucci D et al. Effects of rosuvastatin on atrial fibrillation occurrence: ancillary results of the GISSI-HF trial. Eur Heart J, 2009; 30: 2327-2336.

81. Lau DH, Psaltis PJ, Carbone A et al. Atrial protective effects of n-3 polyunsaturated fatty acids: A long term study in ovine chronic heart failure. Heart Rhythm, 2011; 8: 575-582.

82. Fox K, Ford I, Steg PG, Tendera M, Robertson M, Ferrari R. Heart rate as a prognostic risk factor in patients with coronary artery disease and left-ventricular systolic dysfunction (BEAUTIFUL): A subgroup analysis of a randomised controlled trial. Lancet, 2008; 372: 817-821.

83. Swedberg K, Komajda M, Böhm M et al. Ivabradine and outcomes in chronic heart failure (SHIFT): A randomised placebocontrolled study. Lancet, 2010; 376: 875-885.

84. Ranolazine Implantable Cardioverter-Defibrillator Trial (RAID) 2011. Identifier: NCT01215253 Cg.

85. Maisel WH, Stevenson LW. Atrial fibrillation in heart failure: Epidemiology, pathophysiology, and rationale for therapy. Am J Cardiol, 2003; 91: 2D-8D.

86. Andersen M, Videbaek R, Boesgaard S, Sander K, Hansen PB, Gustafsson F. Incidence of ventricular arrhythmias in patients on long-term support with a continuous-flow assist device (HeartMate II). J Heart Lung Transplant, 2009; 28: 733-735.

87. Boyle A. Arrhythmias in patients with ventricular assist devices. Curr Opin Cardiol, 2012; 27: 13-18. 